\title{
Soroprevalência de Maedi-visna em rebanhos ovinos do estado do Maranhão, Brasil*
}

\section{Seroprevalence of Maedi-Visna in sheep flocks State of Maranhão, Brazil}

\author{
Whaubtyfran Cabral Teixeira, ${ }^{* *}$ Edisio Oliveira Azevedo, ${ }^{* * *}$ Sérgio Alves Nascimento, ${ }^{* * *}$ Maria Fernanda Vianna Mavulo, ${ }^{* * * *}$ \\ Huber Rizzo, ${ }^{* * * * *}$ Jean Carlos Ramos da Silva, ${ }^{* * * * *}$ Roberto Soares de Castro, ${ }^{* * * * *}$
}

\begin{abstract}
Resumo
Apesar de ter sido relatada em vários estados, não há informação sobre o Vírus da Maedi Visna (MVV) no Maranhão, e com o crescimento de sua ovinocultura, aumenta o fluxo de animais de outras regiões. Com isso objetivou-se determinar a soroprevalência do MVV em rebanhos ovinos das três principais mesorregiões produtoras do estado do Maranhão, através da pesquisa das 1.495 amostras sanguíneas de ovinos, com idade superior a seis meses, pertencentes a 83 rebanhos de 23 municípios das mesorregiões Cento, Leste e Norte. O diagnóstico sorológico da infecção pelo vírus MVV foi realizado por meio do teste de imunodifusão em gel de ágar (micro-IDGA). Constatou-se uma prevalência geral de 0,7\% (IC95\%:0,4-1,3\%) de ovinos soropositivos e prevalências nas mesorregiões Centro, Leste e Norte de 0,5\% (IC95\%:0,1-1,4\%), 0,7\% (IC95\%:0,2-1,8\%) e 1\% (IC95\%:0,3-2,4\%) respectivamente. Em relação à variável sexo, não foi observada diferença significativa $(P>0,05)$ entre machos $(0,5 \%, I C 95 \%: 0-2,7 \%)$ e fêmeas (0,8\%, IC95\%:0,4-1,4\%), assim como quanto a genética comparando-se ovinos de raças puras (1,5\%, IC $95 \%$ : 0,4-8,1\%), mestiços $(1 \%, I C 95 \%: 0,4-2,0 \%)$ e SRD (0,3\%, IC95\%:0,04-1,1\%). A análise quanto à idade não demonstrou diferença significante $(\mathrm{P}>0,05)$. Conclui-se que a infecção pelo MVV está presente em ovinos das mesorregiões estudadas, sendo este o primeiro registro desta enfermidade no estado do Maranhão. Considerando a baixa prevalência, é necessário evitar a introdução e a propagação do vírus entre os rebanhos, através da exigência de testes negativos para MVV e descarte dos ovinos positivos.
\end{abstract}

Palavras-chave: epidemiologia, imunodifusão em gel ágar, lentiviroses, pequenos ruminantes, pneumonia progressiva ovina.

\begin{abstract}
Although it has been reported in several states, no information about Maedi-Visna (MV) in the state of Maranhão is available. The aim of the present study was to determine the seroprevalence of Maedi Visna Virus (MVV) in sheep flocks of the three most important sheep rearing areas from Maranhão State, Brazil. We surveyed 1.495 blood samples from sheep older than six months, of both sexes and various breeds. The samples were collected from 83 herds of 23 municipalities present in the Central, East and North regions of Maranhão. The immunodifusion agar gel (micro-AGID) performed serological diagnosis of infection MVV. The statistical analysis was performed by Fisher's test, using Epi Info. It was found an overall prevalence of MVV infection of $0,7 \%$ (Cl95\%:0,4-1,3\%) the ovines and prevalence of 0,5\% (Cl95\%:0,1-1,4\%), 0,7\% (CI95\%:0,2-1,8\%) e 1\% (Cl95\%:0,3-2,4\%) in the Central, East and North regions, respectively. In relation to sex, there wasn't a significant difference (P>0.05) between males (0,5,\%, CI95\%:0-2,7\%) and females (0,8\%, CI95\%:0,4-1,4\%), as well as in relation to genetic comparing sheep purebreds (1,5\%, CI95\%:0,4-8,1\%), crossbred (1\%, CI95\%:0,4-2,0\%) and SRD (0,3\%, IC95\%:0,04-1,1\%). In relation to age wasn't observed significant difference. It has concluded that infection with MVV is present in the studied population in low prevalence. This is the first record of MVV in sheep in the State of Maranhão. Considering the low prevalence is necessary to prevent the introduction and spread of the virus between flocks by requiring negative tests for MVV and disposal of positive sheep.
\end{abstract}

Keywords: epidemiology, agar gel immunodiffusion, lentivirosis, small ruminants, ovine progressive pneumonia.

\section{Introdução}

O estado do Maranhão apresenta grande potencialidade para o desenvolvimento da ovinocultura, uma vez que suas características edafoclimáticas são favoráveis. No entanto, o estado possui um dos menores rebanhos ovinos da região Nordeste, com 230.695 animais, dos quais $54,7 \%$ estão localizados nas mesorregiões Leste, Norte e Centro Maranhense, com $23,1 \%, 19,6 \%$ e $12 \%$ dos ovinos respectivamente, sendo o restante criados nas mesorregiões Oeste e Sul (IBGE, 2006). Devido ao aumento do fluxo de importação de ovinos de outras regiões (Teixeira et al., 2015), objetivando melhorar a produtividade, torna-se relevante o conhecimento do perfil sanitário dos rebanhos, para o controle da introdução de enfermidades, merecendo atenção especial a Maedi-Visna (MV) (Callado et al., 2001; Castro e Melo, 2001) que é uma doença

\footnotetext{
${ }^{*}$ Recebido em 8 de maio de 2015 e aceito em 18 de junho de 2016.

**Pós-graduando do Programa Ciência Animal, Departamento de Medicina Veterinária - UFRPE, Recife, PE.

***Docente da Universidade Federal de Sergipe - UFS - São Cristovão, SE.

${ }^{* * * *}$ Técnico do Laboratório de Viroses do Departamento de Medicina Veterinária - UFRPE, Recife, PE

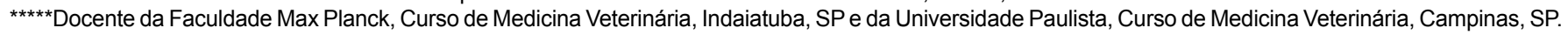

***** Docente do Departamento de Medicina Veterinária - UFRPE, Recife, PE

Autor para correspondência: hubervet@gmail.com
} 
multissistêmica, crônica e progressiva, causada por lentivírus, o vírus Maedi-Visna (MVV), pertencente à família Retroviridae, que acomete os ovinos e caprinos provocando grandes perdas econômicas, infectando animais independentemente do sexo, raça e tipo de exploração (Brodie et al., 1998; Castro et al., 1999; Callado et al., 2001).

A disseminação do MVV nos rebanhos ocorre após a introdução de novos animais, infectados e geralmente assintomáticos, que se tornarão reservatórios e fonte de infecção transmitindo o agente por meio de secreções ou excreções, ricas em células do sistema monocíticofagocitário, através de fômites (Blacklaws et al., 2004), via vertical (Cutlip et al., 1981; Brodie et al., 1994), digestiva com a absorção do vírus pela mucosa intestinal e disseminação pelos linfonodos mesentéricos, após ingestão de colostro e/ou leite contaminado (Preziuso et al., 2004) e pela inalação de aerossóis contendo MVV principalmente em sistemas de confinamento (Concha-Bermejillo, 1997; McNeilly et al., 2008). Pode ainda ocorrer a transmissão interespécie com caprinos infectados por algum dos lentivírus de pequenos ruminantes (Castro et al., 1999; Souza et al., 2012).

Os sinais clínicos da infecção são artrite, dificuldade de locomoção, dispneia, encefalite, linfadenopatia, mastite, emagrecimento progressivo e pneumonia intersticial crônica (Araújo et al., 2004a; Glaria et al., 2012; Pérez et al., 2014). O diagnóstico de MV por meio de testes laboratoriais, como os testes de imunodifusão em gel de ágar (IDGA), ELISA, isolamento, reação de cadeia de polimerase e imunohistoquímica torna-se relevante pois muitos animais não apresentam sinais clínicos ou às vezes estes podem demorar para aparecer, devido ao próprio caráter crônico da enfermidade (Callado et al., 2001; Glaria et al., 2012).

No Brasil, o primeiro registro de ovinos soropositivos ocorreu no Rio Grande do Sul (Dal Pizzol et al., 1989). Em seguida, vários estudos soroepidemiológicos foram realizados em ovinos, por meio do IDGA, em diversos estados do Nordeste como Bahia (Souza et al., 2007; Barros et al., 2010; Martinez et al., 2011), Ceará (Almeida et al., 2003; Araújo et al., 2004b; Alves et al., 2011), Pernambuco (Oliveira et al., 2006; Costa et al., 2007; Landim et al., 2011), Piauí (Batista et al., 2004; Sampaio Júnior, 2007; Sousa et al., 2011), Sergipe (Melo et al., 2003; Mendonça et al., 2013; Rizzo et al., 2015) e Tocantins (Sobrinho et al., 2008). Considerando a relevância da ovinocultura para o Maranhão aliada a inexistência de dados epidemiológicos sobre a MV no estado, o presente estudo foi conduzido com o objetivo de determinar a soroprevalência do MVV em rebanhos das três principais mesorregiões produtoras de ovinos do Maranhão.

\section{Material e métodos}

O estudo foi realizado no estado do Maranhão (0505'12" S e $42^{\circ} 48^{\prime} 42^{\prime \prime}$ O) que possui área territorial de aproximadamente $331.918 \mathrm{~km}^{2}$, é dividido em cinco mesorregiões (Centro, Leste, Norte, Oeste e Sul) e possui um efetivo ovino de aproximadamente 230.695 animais, constituído por animais com aptidão para produção de carne e pele (GEPLAN, 2002; IBGE, 2006).

Entre os meses de maio de 2011 a fevereiro de 2012, foram coletadas 1.495 amostras de sangue ovinos de 83 propriedades, com sistema de exploração semiextensivo $(n=79)$ e intensivo $(n=4)$, localizadas em 23 municípios das mesorregiões; Centro $(n=564)$, Leste $(n=539)$ e Norte $(n=392)$, abrangendo dez unidades regionais de acordo com a divisão administrativa da Agência Estadual de Defesa Agropecuária do Maranhão (AGED/ MA) - Bacabal, Caxias, Chapadinha, Codó, Itapecuru Mirim, Pedreiras, Presidente Dutra, Barra do Corda, Rosário e São João dos Patos (Figura 1).

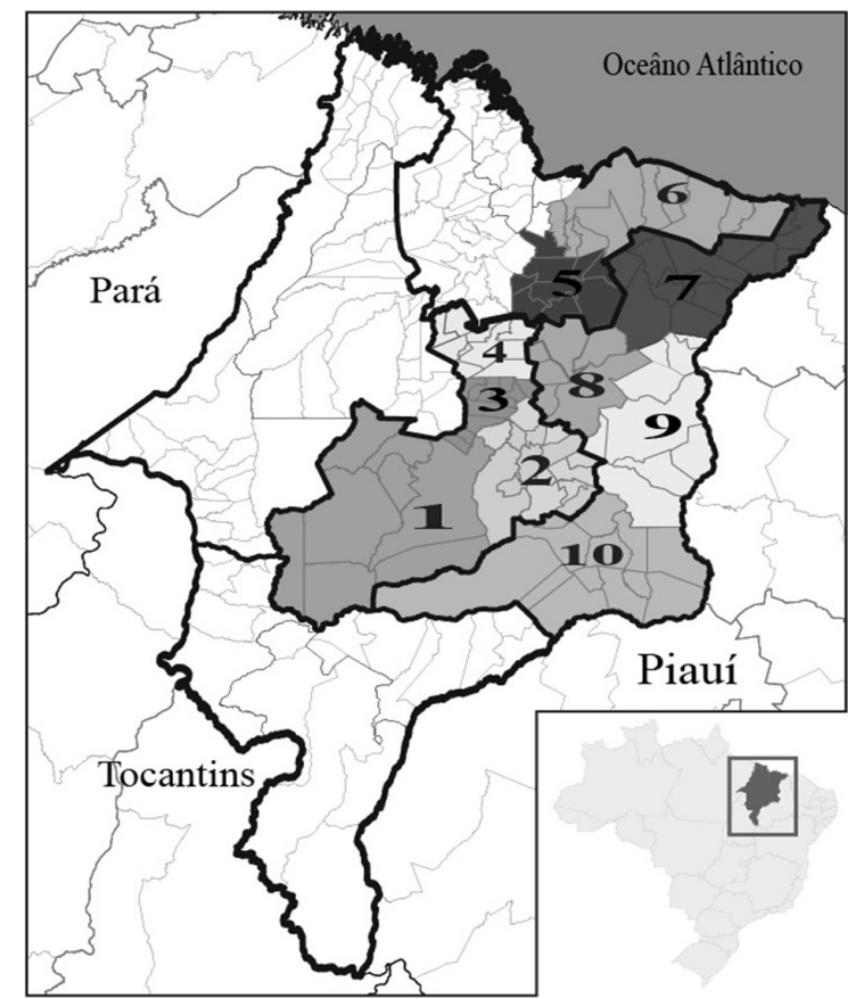

Figura 1: Mapa do estado do Maranhão dividido em suas cinco mesorregiões demonstrando as dez regionais da AGED/MA onde foram coletadas amostras de ovinos para pesquisa do MVV, sendo: Barra do Corda (1), Presidente Dutra (2), Pedreiras (3) e Bacabal (4) da mesorregião Centro, Itapecurú Mirím (5), Rosário (6) e Chapadinha (7) da mesorregião Norte e Codó (8), Caxias (9) e São João dos Patos (10) da mesorregião Leste.

Diante desta população ovina, realizou-se o cálculo amostral para a determinação da prevalência de animais positivos para MVV em cada mesorregião. Sendo que, para o cálculo do tamanho da amostra foi utilizada a fórmula $\mathrm{N}=\mathrm{Z}^{2} \times \mathrm{P}(1-\mathrm{P})$ / $\mathrm{e}^{2}$, admitindo um grau de confiança de $95 \%(Z)$, erro amostral de $5 \%$ (e) e prevalência esperada de $50 \%$, a fim de maximizar a amostra. Com base nesses parâmetros, a amostra mínima obtida foi de 384 animais para cada mesorregião (Dean et al., 2002), e considerando-se 15 como número mínimo de amostras por criação, chega-se ao número de 26 a serem amostradas por mesorregião. O total de amostras em cada criação foi assim distribuído: $10 \%$ reprodutores, $20 \%$ jovens (entre seis e 12 meses) e 70\% matrizes. A escolha dos municípios e das propriedades em cada regional da AGED/MA estudada foi realizada de acordo com a divisão do estado, conveniência, facilidade de acesso e a disponibilidade dos produtores. Os animais a serem testados foram selecionados aleatoriamente. Foram utilizados ovinos de ambos os sexos, de diferentes 
padrões zootécnicos, predominantemente mestiços, raças puras (Santa Inês, Dorper, Texel e Somalis) e sem raça definida (SRD), aparentemente saudáveis, com idade superior a seis meses. A idade dos animais foi estimada baseando-se na cronologia dentária (Silva et al., 2001).

Para detecção de anticorpos contra o MVV, foi utilizada a técnica de microimunodifusão em gel de ágar (micro-IDGA), recomendada pela OIE, utilizando-se antígeno produzido pelo Laboratório Biovetech (Recife-PE, Brasil), realizada de acordo com as recomendações do fabricante.

Para a análise estatística dos dados obtidos, foi utilizado o teste exato de Fisher, com nível de significância de 5\%, empregandose o programa Epi Info Versão 6.04d (CDC, Atlanta, GA, USA) (Dean et al., 2002).

\section{Resultados e discussão}

No resultado da análise das amostras de soro de ovino, observou-se uma prevalência geral de MVV de 0,7\% (IC95\%:0,4$1,3 \%$ ) e prevalências de 0,5\% (IC95\%:0,1-1,4\%), 0,7\% (IC95\%:0,2-1,8\%) e 1\% (IC95\%:0,3-2,4\%) nas mesorregiões Centro, Leste e Norte, respectivamente, não sendo verificada diferença estatística significativa $(P>0,05)$ (Tabela 1).

Tabela 1: Distribuição de frequências de ovinos soropositivos à imunodifusão em gel de ágar (micro-IDGA) para Maedi-Visna, de acordo com as regionais, das mesorregiões Centro, Leste e Norte no estado do Maranhão

\begin{tabular}{cccc}
\hline \multirow{2}{*}{ Mesorregião } & Regional AGED/MA & \multicolumn{2}{c}{ Resultado da micro-IDGA } \\
\cline { 3 - 4 } & & $\begin{array}{c}\% \text { (positivos /total } \\
\text { amostras) }\end{array}$ & $\begin{array}{c}\text { Intervalo de } \\
\text { Confiança } 95 \%\end{array}$ \\
\hline Norte & Itapecuru Mirim & $1,9 \%(3 / 161)$ & $0,5-5,0$ \\
Lubtotal & Rosário & $0,4 \%(1 / 231)$ & $0,0-2,1$ \\
& & $1,0 \%(4 / 392)^{\mathrm{a}}$ & $0,3-2,4$ \\
\hline Subtotal & Caxias & $0,0 \%(0 / 110)$ & $0,0-2,7$ \\
& Chapadinha & $0,0 \%(0 / 143)$ & $0,0-2,1$ \\
\hline Centro & Codó & $1,3 \%(2 / 150)$ & $0,2-4,3$ \\
& São João dos Patos & $1,5 \%(2 / 136)$ & $0,2-4,8$ \\
& & $0,7 \%(4 / 539)^{\mathrm{a}}$ & $0,2-1,8$ \\
\hline Total & Bacabal & $0,0 \%(0 / 141)$ & $0,0-2,1$ \\
& Barra da Corda & $0,0 \%(0 / 154)$ & $0,0-1,9$ \\
& Pedreiras & $2,2 \%(3 / 138)$ & $0,6-5,8$ \\
\hline \multirow{2}{*}{ Subtotal } & Presidente Dutra & $0,0 \%(0 / 131)$ & $0,0-2,3$ \\
\hline
\end{tabular}

Letras minúsculas distintas na mesma coluna indicam diferença estatisticamente significativa (Qui-quadrado, $P<0,05$ ).

Em relação ao total de propriedades amostradas, constatouse que $9,6 \%(8 / 83)$ apresentaram pelo menos um animal soropositivo, sendo duas no município de Vargem Grande e uma em cada um dos seguintes municípios: Codó, Igarapé Grande, Paraibano, Pedreiras, São João dos Patos e Timbiras.
Dos municípios pesquisados, 30,4\% (7/23) apresentaram pelo menos uma propriedade com animal soropositivo, demonstrando que embora baixa, a prevalência encontrada é relevante, pois confirma a circulação do MVV nas três mesorregiões estudadas. Outros trabalhos também têm relatado taxas de prevalências baixa ou nula, tais como de Souza et al. (2007) e Martinez et al. (2011) na Bahia (0,5\% e 0,34\%), Sampaio Junior (2007) e Sousa et al. (2011) no Piauí (0,6\% e 0,5\%), Mendonça et al. (2013) e Rizzo et al., (2015) no Sergipe (0,7\% e 1,5\%), Sobrinho et al. (2008) no Tocantins (0,9\%), Costa et al. (2007) em Pernambuco $(1,1 \%)$, Salaberry et al. (2010) em Minas Gerais (0\%) e Lara et al., (2012) e Gregory et al., (2013) (0,3\% e 0\%) em São Paulo. Resultados superiores foram descritos por Oliveira et al. (2006), Araújo et al. (2004b) e Barioni et al. (2009), em ovinos do estado de Pernambuco, Ceará e Espírito Santo, onde observaram prevalências de 3,8\%, 4,9\% e 7,33\% para MVV, por meio também da IDGA, respectivamente. Pesquisa recente da infecção pelo vírus da Arterite Encefalite Caprina em caprinos criados no Maranhão, demonstrou uma baixa prevalência de 2,8\% (47/1703), havendo com isso um baixo risco de infecção interespécie (Teixeira et al., 2016).

A baixa prevalência encontrada no presente estudo, porém, significativa já que se trata de uma doença que pode provocar perdas econômicas e repercussão internacional, pode estar relacionada com a dinâmica da exploração da espécie voltada para o corte e devido aos rebanhos estarem ainda em formação com predomínio de animais mestiços e SRD, aliado ao sistema de criação não tecnificada adotado no estado, sendo o vírus introduzido recentemente nessas mesorregiões através da aquisição de animais procedentes de rebanhos e/ou regiões que não se tem conhecimento real da situação epidemiológica desta infecção, como relatado em outros países (Blacklaws et al., 2004; Teixeira et al., 2015). Para que esses rebanhos, ainda em formação, tenham controle do MVV devem-se adotar um sistema de segregação, com base em testes sorológicos, identificando os soropositivos e os removendo do rebanho para lotes separados dos animais negativos, para que sejam abatidos gradualmente. Os testes diagnósticos, dentre eles o sorológico, são importantes devido à manifestação insidiosa dos sinais clínicos da doença, dificultando a identificação dos reservatórios no rebanho, no entanto o mesmo possui valor limitado na identificação de animais em fase inicial da infecção (Dantas et al., 2005). Outras medidas de controle da infecção são a seleção de borregas de reposição soronegativas, o fornecimento de colostro e leite, de ovelhas soronegativas ou termicamente tratados e o uso de agulhas e materiais cirúrgicos descartáveis e/ ou estéreis (Callado et al., 2001; Lara, 2006; Pérez et al., 2013).

Em relação ao sistema de criação predominante nesse estudo, o semiextensivo, a prevalência observada se assemelha à verificada em outros Estados do Nordeste que estudaram rebanhos com o mesmo tipo de criação (Teixeira et al., 2015; Martinez et al., 2011; Alves et al., 2011; Landim et al., 2011; Sousa et al., 2011; Rizzo et al., 2015; Sobrinho et al., 2008). A criação semiextensiva e extensiva de ovinos, reduz os riscos de transmissão horizontal, via aerossóis, 
intensificada em períodos onde os mesmos são confinados (Concha-Bermejillo, 1997).

Quanto ao sexo dos ovinos soropositivos, 0,5\% (IC95\%:0-2,70\%) eram machos e 0,8\% (IC95\%:0,4-1,4\%) fêmeas, não havendo diferença significativa $(P>0,05)$ (Tabela 2), assim como observado por outros autores em estudos de rebanhos nacionais (Oliveira et al., 2006; Sobrinho et al., 2008; Lombardi et al., 2009). Informações de que fêmeas permanecem mais tempo nas criações do que os machos destinados ao abate e que reprodutores são mantidos separados ou ainda possam ser emprestados a outros criatórios para a monta, não influenciaram na predisposição da infecção pelo MVV.

A soroprevalência, de acordo com a idade (Tabela 3), demonstrou que não houve diferença estatística significativa $(P>0,05)$, corroborando com outros estudos (Araújo et al., 2004b; Oliveira et al., 2006; Sobrinho et al., 2008). Esse resultado pode ser esclarecido uma vez que a enfermidade possui caráter lento e o tempo de exposição ao agente viral é um fator muito importante para a soroconversão. O aumento da soroprevalência em animais jovens poderia ser observado somente se a taxa de infecção fosse alta nos rebanhos (East et al., 1987; Houwers e Van der Molen, 1987).

Com relação à variável grupo genético foi observada soroprevalência de 1,5\% (IC95\%:0,4-8,1\%), 1,0\% (IC95\%:0,4-2,0\%) e $0,3 \%$ (IC95\%:0,04-1,1\%) para animais de raças puras (Dorper, Santa Inês, Somalis e Texel), mestiços e SRD, respectivamente, não havendo associação entre a soropositividade e a raça acometida $(P>0,05)$ (Tabela 4$)$.

Os resultados encontrados no trabalho corroboram com obtidos por Sobrinho et al. (2008) e Lombardi et al. (2009) os quais verificaram, no Tocantins e em São Paulo, respectivamente, que a prevalência de animais positivos ao MVV não diferiu com relação ao grau de pureza da raça. A baixa prevalência deve-se provavelmente à predominância de animais mestiços e SRD, tornando-se relevante a exigência, quando da aquisição (compra ou empréstimo) de matrizes e reprodutores de raças melhoradores, dos exames que comprovem a soronegatividade para a infecção por MVV.

\section{Conclusão}

Conclui-se que a infecção pelo MVV está presente em ovinos das mesorregiões estudadas, com baixa prevalência, não havendo relação com as variáveis sexo, idade e raça. Este é o primeiro $P<0,05)$.
Tabela 2: Distribuição de frequência de ovinos soropositivos à imunodifusão em gel de ágar (micro-IDGA) para Maedi-Visna, de acordo com o sexo, no Estado do Maranhão

\begin{tabular}{ccc}
\hline Sexo & \multicolumn{2}{c}{ Resultado da micro-IDGA } \\
\cline { 2 - 3 } & $\%$ (positivos /total amostras) & Intervalo de Confiança $95 \%$ \\
\hline Fêmea & $0,8 \%(10 / 1288)^{\mathrm{a}}$ & $0,4-1,4$ \\
Macho & $0,5 \%(1 / 207)^{\mathrm{a}}$ & $0,0-2,70$ \\
Total & $0,7 \%(11 / 1495)$ & $0,4-1,3$ \\
\hline
\end{tabular}

Letras distintas na mesma coluna indicam diferença estatisticamente significativa (qui-quadrado;

Tabela 3: Distribuição de frequência de ovinos soropositivos à imunodifusão em gel de ágar (micro-IDGA) para Maedi-Visna, de acordo com a idade, estimada segundo Silva et al. (2001), no Estado do Maranhão

\begin{tabular}{ccc}
\hline \multirow{2}{*}{$\begin{array}{c}\text { Muda } \\
\text { (Idade em meses) }\end{array}$} & \multicolumn{2}{c}{ Resultado da micro-IDGA } \\
\cline { 2 - 3 } Dente de leite (até 12) & $0,8 \%(2 / 257)^{\mathrm{a}}$ & $0,1-2,8$ \\
Primeira (16) & $1,3 \%(3 / 232)^{\mathrm{a}}$ & $0,3-3,7$ \\
Segunda (23) & $0,6 \%(2 / 311)^{\mathrm{a}}$ & $0,1-2,2$ \\
Terceira (29) & $0,4 \%(2 / 497)^{\mathrm{a}}$ & $0,1-1,4$ \\
Quarta (40) & $1,1 \%(2 / 178)^{\mathrm{a}}$ & $0,1-3,9$ \\
Total & $0,7 \%(11 / 1495)$ & $0,4-1,3$ \\
\hline
\end{tabular}

Letras minúsculas iguais na mesma coluna indicam que não houve diferença estatisticamente significativa (de acordo com o qui-quadrado, $\mathrm{P}>0,05$ ).

Tabela 4: Distribuição de frequência de ovinos soropositivos à imunodifusão em gel de ágar (micro-IDGA) para Maedi-Visna, de acordo com o grau de sangue/raça, no Estado do Maranhão, 2012

\begin{tabular}{ccc}
\hline Muda & \multicolumn{2}{c}{ Resultado da micro-IDGA } \\
\cline { 2 - 3 } (Idade em meses $^{*}$ & $\%$ (positivos /total amostras) & Intervalo de Confiança $95 \%$ \\
\hline SRD & $0,3 \%(2 / 653)^{\mathrm{a}}$ & $0,04-1,1$ \\
Mestiço & $1,0 \%(8 / 776)^{\mathrm{a}}$ & $0,4-2,0$ \\
Raças Puras & $1,5 \%(1 / 66)^{\mathrm{a}}$ & $0,4-8,1$ \\
Total & $0,7 \%(11 / 1495)$ & $0,4-1,3$ \\
\hline
\end{tabular}

Letras distintas na mesma coluna indicam diferença estatisticamente significativa (de acordo com quiquadrado, $\mathrm{P}<0,05$ ).

registro desta enfermidade em ovinos no estado do Maranhão, e considerando a baixa prevalência, faz-se necessário o controle da introdução e disseminação do vírus entre os rebanhos do estado, através da exigência de testes negativos para MVV. Importante destacar que a MV é considerada de notificação obrigatória junto à Organização Mundial de Saúde Animal (OIE), uma vez que pode trazer riscos ao comércio internacional de ovinos (OIE, 2012). 


\section{Referências}

ALMEIDA, N.C.; TEIXEIRA, M.F.S.; FERREIRA, R.C.S.; CALLADO, A.K.C.; FROTA, M.N.L.; MELO, A.C.M.; APRÍGIO, C.J.L. Detecção de ovinos soropositivos para Maedi/Visna destinados ao abate na região metropolitana de Fortaleza. Veterinária Notícias, v. 9, n. 1, p. 59-63, 2003.

ALVES, F.S.F.; SANTIAGO, L.B.; LIMA, A.M.C.; FARIAS, D.A.; PINHEIRO, R.R.; CAVALCANTE, A.C.R. Inquérito sorológico da infecção pelos lentivírus de pequenos ruminantes em rebanhos de caprinos e ovinos de quatro mesorregiões do estado do Ceará, Brasil. O Biológico, v. 73, n. 2, p. 34, 2011.

ARAÚJO, S.A.C.; DANTAS, T.V.M.; SILVA, J.B.A.; RIBEIRO, A.L.; RICARTE, A.R.F.; TEIXEIRA, M.F.S. Identificação do Maedi-Visna vírus em pulmão de ovinos infectados naturalmente. Arquivos do Instituto Biológico, v.71, n. 4, p. 431-436, 2004a.

ARAÚJO, S.A.C.; DANTAS, T.V.M.; TEIXEIRA, M.F.S.; S ILVA, J.B.A.; RIBEIRO, A.L.; SOUZA, A.C.F.R. Levantamento sorológico de Maedi-Visna em ovinos de abatedouros da Região Metropolitana de Fortaleza-CE. In: Congresso Brasileiro de Medicina Veterinária, 31., 2004, São Luís, MA. Resumos. São Luís, 2004b.

BARIONI, G.; PEREIRA, L.V.; BELTRAME, M.A.V.; TESOLINE, P.; GUMIEIRO, M.V. Soroprevalência de Maedi-Visna em ovinos da raça Santa Inês nos municípios da Grande Vitória-ES. Ciência Animal Brasileira, Suplemento 1, p. 579-584, 2009.

BARROS, I.N.; SILVA, N.S.; ALMEIDA, M.G.A.R.; ANUNCIAÇÃO, A.V.M.; LABORDA, S.S.; RAMALHO, E.J.; OLIVEIRA, E.M.D. Detection of antibodies to Visna/Maedi in sheep from Recôncavo Baiano. Revista Ciências Agrárias, v. 53, n. 2, p. 206-211, 2010.

BATISTA, M.C.S.; CASTRO, R.S.; C ARVALHO, F.A.A.; C RUZ, M.S.P.; RÊGO, E.W.; SILVA, S.M.M.S.; OLIVEIRA, R.A.; LOPES, J.B. Pesquisa de anticorpos anti-lentivírus de pequenos ruminantes em ovinos, no Estado do Piauí, Brasil. In: CONGRESSO BRASILEIRO DE MEDICINA VETERINÁRIA, 31., 2004, São Luís, MA. Resumos. São Luís, 2004.

BLACKLAWS, B.A.; BERRIATUA, E.; TORSTEINSDOTTIR, S.; WATT, N.J.; ANDRES, D.; KLEIN, D.; HARKISS, G.D. Transmission of small ruminant lentiviruses. Veterinary Microbiology, v. 101, p. 199-208, 2004

BRODIE, S.J.; DE LA CONCHA-BERMEJILLO, A.; KOENIG, G.; SNOWDER, G.D.; DEMARTINI, J.C. Maternal factors associated with prenatal transmission of ovine lentivirus. The Journal of Infectious Diseases, v. 169, p. 653-657, 1994.

BRODIE, S.J.; CONCHA-BERMEJILLO, A.; SNOWDER, G.D. Current concepts in the epizootiology, diagnosis, and economic importance of ovine progressive pneumonia in North America: a review. Small Ruminant Research, v. 27, p. 1-17, 1998.

CALLADO, A.K.C.; CASTRO, R.S.; TEIXEIRA, M.F.S. Lentivírus de pequenos ruminantes (CAEV e Maedi-Visna): revisão e perspectiva. Pesquisa Veterinária Brasileira, v. 21, n. 3, p. 87-97, 2001.CASTRO, R.S.; GREENLAND, T.; LEITE, R.C.; GOUVEIA, A.M.J.; MORNEX, J.F.; CORDIER, G. Conserved sequence motifs involving the tat reading frame of Brazilian caprine lentiviruses indicate affiliations to both caprine arthritisencephalitis virus and visna-maedi virus. Journal of General Virology, v. 80, p. 15831589, 1999.

CASTRO, R.S.; MELO, L.E.H. CAEV e Maedi-Visna: importância na saúde e produtividade de caprinos e ovinos e a necessidade de seu controle no Nordeste Brasileiro. Ciência Veterinária nos Trópicos, v. 4, n. 2/3, p. 315-320, 2001.
CONCHA-BERMEJILLO A. Maedi-visna and ovine progressive pneumonia. Veterinary Clinics of North America: Food Animal Practice, v. 13, p. 12-33, 1997.

COSTA, L.S.P.; LIMA, P.P.; CALLADO, A.K.C.; NASCIMENTO, S.A.; CASTRO, R.S. Lentivírus de pequenos ruminantes em ovinos Santa Inês: isolamento, identificação pela PCR e inquérito sorológico no Estado de Pernambuco. Arquivos do Instituto Biológico, v. 74, n. 1, p. 11-16, 2007.

CUTLIP, R.C.; LEHMKUHL, H.D.; JACKSON, T.A. Intrauterine transmission of ovine progressive pneumonia virus. American Journal Veterinary Research, v. 42, p. 1795-1797, 1981.

DAL PIZZOL, M.; RAVAZZOLO, A.P.; GONÇALVES, I.P.D.; HOTZEL, I.; FERNANDES, J.C.T.; MOOJEN, V. Maedi-Visna: evidência de ovinos infectados no Rio Grande do Sul, Brasil, 1987-1989. Arquivos da Faculdade de Veterinária UFRGS, v.17, p. 65-76, 1989.

DANTAS, T.V.M.; ARAÚJO, S.A.C.; SILVA, J.B.A.; RICARTE, A.R.F.; TEIXEIRA, M.F.S. Formas de diagnóstico da Maedi-Visna. Ciência Animal, v.15, n. 2, p. 89-97, 2005.

DEAN, A.G.; DEAN, J.A.; BURTON, A.H. Epi Info 6, Version 1.2: A Word Processing, Data Base and Statistic Program for Epidemiology on Microcomputers. Centers for Disease Control, Atlanta. 2002.

EAST, N.E.; ROWE, W.J.; MADEWELL, B.R.; FLOYD, K. Serologic prevalence of caprine arthritis-encephalitis virus in California goat dairies. Journal of de American Veterinary Medical Association, v.190, n. 2, p. 182-186, 1987.

GEPLAN, 2002. Atlas do Maranhão. Laboratório de Geoprocessamento, Gerência de Planejamento e Desenvolvimento Econômico, UEMA. Geplan, São Luís. 44 p.

GLARIA, I.; REINA, R.; RAMÍREZ, H.; ANDRÉS, X.; CRESPO, H.; JAUREGUI, P.; SALAZAR, E.; LUJÁN, L.; PÉREZ, M.M.; BENAVIDES, J.; PÉREZ, V.; POLLEDO, L.; GARCÍA-MARÍN, J.F.; RIEZU, J.I.; BORRÁS, R.; AMORENA, B.; ANDRÉS, D. Visna/ Maedi virus genetic characterization and serological diagnosis of infection in sheep from a neurological outbreak. Veterinary Microbiology, v. 155, p. 137-146, 2012.

GREGORY, L.; LARA, M.C.C.S.H.; KIRALY, A.C.M.; HASEGAWA, M.Y.; RIZZO, H.; HENRIQUES, L.C.S.; ROSSI, R.S.; CASTRO, R.S. Pesquisa de anticorpos contra maedi-visna em ovinos nas microrregiões de Botucatu, Campinas, Piedade e São Paulo, Estado de São Paulo. Arquivos do Instituto Biológico, v. 80, n. 1, p. 107-110, 2013.

HOUWERS, D.J.; VAN DER MOLEN, E.J. A five-year serological study of natural transmission of maedi-visna virus in a flock of sheep, completed with post mortem investigation. Journal of Veterinary Medicine Series B, v. 34, p. 421-431, 1987.

IBGE (Instituto Brasileiro de Geografia e Estatística). Censo Agropecuário 2006 - Rebanho caprino. Acesso em 01 Out. 2013. Avaliable from: < http://www.ibge.gov.br >

LANDIM, A.M.S.; VESCHI, J.L.A.; MARTINS, R.J.; ZAFALON, L.F.; CASTRO, R.S. Avaliação da ocorrência de anticorpos contra o vírus da Maedi-Visna em ovinos do município de Dormentes PE. In: JORNADA DE INICIAÇÃO CIENTÍFICA DA EMBRAPA, 6. , 2011, Petrolina. Anais...Petrolina: Embrapa Semiárido, 2011, p. 405-411.

LARA, M.C.C.S.H. Artrite-encefalite dos caprinos. Biológico, v. 68, n. 1/2, p. 21-23, 2006. 
LARA, M.C.C.S.H.; VILLALOBOS, E.M.C.; CUNHA, E.M.S.; CHIEBAO, D.; GABRIEL, F.H.; PAULIN, L.; CASTRO, V.; NASSAR, A.F.C.; PIATTI, R.; OKUDA, L.; ROMALDINI, A.H.C.N.; FEDERSONI, I.S.P.; LUCCHESE FILHO, A.; FELÍCIO, A.L.A.; PINO, F.A.; AZEVEDO, S.S.; CARDOSO, M.V. Inquérito sorológico de lentiviroses de pequenos ruminantes (Maedi-Visna e artrite-encefalite caprina) no estado de São Paulo. Brazilian Journal Veterinary Research Animal Science, v. 50, n. 1, p. 1825, 2013.

LOMBARDI, A.L.; NOGUEIRA, A.H.C.; FERES, F.C.; PAULO, H.P.; CASTRO, R.S.; FEITOSA, F.L.F.; CADIOLI, F.A.; PEIRÓ, J.R.; PERRI, S.H.V.; LIMA, V.F.M.; MENDES, L.C.N. Soroprevalência de Maedi-Visna em ovinos na região de Araçatuba, SP. Arquivo Brasileiro de Medicina Veterinária e Zootecnia, v. 61, n. 6, p. 1434-1437, 2009.

MARTINEZ, P.M.; COSTA, J.N.; SOUZA, T.S.; LIMA, C.C.V.; NETO, A.O.C. PINHEIRO, R.R. Prevalência sorológica da MaediVisna em rebanhos ovinos da microrregião de Juazeiro - Bahia por meio do teste de imunodifusão em gel de ágar. Ciência Animal Brasileira, v. 12, n. 2, p. 322-329, 2011.

MCNEILLY, T.N.; BAKER, A.; BROWN, J.K.; COLLIE, D.; MACLACHLAN, G.; RHIND, S.M.; HARKISS, G.D. Role of Alveolar Macrophages in Respiratory Transmission of Visna/ Maedi Virus. Journal of Virology, v. 82, n. 3, p.1526-1536, 2008.

MELO, C.B.; CASTRO, R.S.; OLIVEIRA, A.A. FONTES, L.B.; CALLADO, A.K.; NASCIMENTO, S.A.; MELO, L.E.H.; SILVA, J.S. Estudo preliminar sobre a infecção por lentivírus de pequenos ruminantes em ovinos e caprinos em Sergipe. In: CONGRESSO LATINO-AMERICANO DE BUIATRIA, 11., 2003, Salvador. Anais... Salvador: Associação Baiana de Buiatria, 2003. p. 47.

MENDONÇA, C.E.D.; BARROS, S.L.B.; MENDONÇA, M.A.D.; GUIMARÃES, V.A.A.; PINHEIRO, R.R. Ocorrência de anticorpos contra o vírus Maedi-Visna em ovinos Santa Inês, no estado de Sergipe, Brasil. Arquivos do Instituto Biológico, v. 80, n. 3, p. 346351, 2013.

OIE. World Organization for Animal Health. Manual of diagnostic tests and vaccines for terrestrial animals. 5. ed. 2004. Disponível em: http://www.oie.int/manual-ofdiagnostic-testsandvaccines-for-terrestrial-animals/>. Acesso em: 20 nov. 2013.

OLIVEIRA, M.M.M.; CASTRO, R.S.; CARNEIRO, K.L.; NASCIMENTO, S.A.; CALLADO, A.K.C.; ALENCAR, C.S.A.; COSTA; L.S.P. Anticorpos contra lentivírus de pequenos ruminantes em caprinos e ovinos em abatedouros do estado de Pernambuco. Arquivo Brasileiro de Medicina Veterinária e Zootecnia, v. 58, n. 5, p. 947-949, 2006.

PÉREZ, M.; BIESCAS, E.; REINA, R.; GLARIA, I.; MARÍN, B.; MARQUINA, A.; SALAZAR, E.; ÁLVAREZ, N.; ANDRÉS, D.; FANTOVA, E.; BADIOLA, J.J.; AMORENA, B.; LUJÁN, L. Small Ruminant Lentivirus-Induced Arthritis: Clinicopathologic Findings in Sheep Infected by a Highly Replicative SRLV B2 Genotype. Veterinary Pathology, v. 29, p. 1-8, 2014.

PREZIUSO, S,; RENZONI, G.; ALLEN, T.E.; TACCINI, E.; ROSSI, G.; DEMARTINI, J.C.; BRACA, G. Colostral transmission of maedi visna virus: sites of viral entry in lambs born from experimentally infected ewes. Veterinary Microbiology, v.104, n. 3-4, p.157-164, 2004.

SOUZA, T.S.; PINHEIRO, R.R.; LIMA, C.C.V.; COSTA, J.N. Transmissão interespécie dos lentivírus de pequenos ruminantes: revisão e desafios. Acta Veterinaria Brasilica, v. 6, n.1, p. 23-34, 2012.
PÉREZ, M.; MUNOZ, J.A.; BIESCAS, E.; SALAZAR, E.; BOLEA, R.; ANDRÉS, D.; AMORENA, B.; BADIOLA, J.J.; REINA, R.; LUJÁN, L. Successful Visna/maedi control in a highly infected ovine dairy flock using serologic segregation and management strategies. Preventive Veterinary Medicine, v.112, p. 423- 427, 2013.

RIZZO, H.; CARVALHO, J. S.; FRAGA, G. J. M.; MAGALHAES, M. V. F.; GOVEIA, A. M. M.; MACHADO, G. M.; SOARES, L. L. S.; OLIVEIRA, C. C. M.; AZEVEDO, S. S.; CASTRO, R. S. Ocorrência de anticorpos contra o Vírus Maedi-Visna em ovinos, no estado de Sergipe, Brasil. In: XI CONGRESSO BRASILEIRO DE BUIATRIA E XVII CONGRESSO LATINOAMERICANO DE BUIATRIA, 11, 2015. São Paulo. Anais... São Paulo: O Biológico. 2015. v. 77 , supl. 2, p.226.

SALABERRY, S.R.S.; LARA, M.C.C.S.H.; PIATTI, R.M.; NASSAR, A.F.C.; CASTRO, J.R.; GUIMARÃES, E.C.; LIMA-RIBEIRO, A.M.C. Prevalência de anticorpos contra os agentes da MaediVisna e Clamidofilose em ovinos no município de Uberlândia, MG. Arquivos do Instituto Biológico, v.77, n. 3, p. 411-417, 2010.

SAMPAIO JÚNIOR, A. Soroprevalência das lentiviroses de pequenos caprinos e ovinos no município de Teresina, Piauí, Brasil. ruminantes em 2007. 68 p. Dissertação (Mestrado em Ciência Animal) - Curso de Pós-Graduação em Ciência Animal. Universidade Federal do Piauí, Teresina.

SILVA, J.V.; RIBEIRO, M.N.; SILVA, L.P.G.; FILHO, E.C.P.; FILHO, A.C.V. Cronologia dentária de caprinos mestiços e naturalizados criados no semi-árido Paraibano. Agropecuária Técnica, v. 22, n. 1/2, p. 45-51, 2001.

SOBRINHO, P.A.M.; FERNANDES, C.H.C.; RAMOS, T.R.R.; CAMPOS, A.C.; COSTA, L.M.; CASTRO, R.S. Prevalência e fatores associados à infecção por lentivírus de pequenos ruminantes em ovinos no Estado do Tocantins. Ciência Veterinária nos Trópicos, v. 11, n. 2/3, p. 65-72, 2008.

SOUSA, M.S.; RÊGO, W.M.F.; SANTOS, R.L.; ALVES, F.S.F.; PINHEIRO, R.R.; FARIAS, D.A.; SANTIAGO, L.B.; DINIZ, B.L.M.; CARDOSO, J.F.S.; PAULA, N.R.O. Soroprevalência dos lentivírus de pequenos ruminantes em ovinos explorados na microrregião do Alto-Médio Gurguéia, no Sul do Estado do Piauí, Brasil. In: CONGRESSO BRASILEIRO DE MEDICINA VETERINÁRIA, 38, 2011, Florianópolis. Anais...Florianópolis: SBMV, 2011, p. 1-3.

SOUZA, T.S.; COSTA, J.N.; MARTINEZ, P.M.; PINHEIRO, R.R. Estudo sorológico da maedi-visna pelo método da imunodifusão em gel de ágar em rebanhos ovinos de Juazeiro, Bahia, Brasil. Revista Brasileira de Saúde e Produção Animal, v. 8, n. 4, p. 276282, 2007.

TEIXEIRA, W.C.; SANTOS, H.P.; SILVA, J.C.R; RIZZO, H.; MARVULO, M.F.V.; CASTRO R.S. Perfil zoosanitário dos rebanhos caprinos e ovinos em três mesorregiões do Estado do Maranhão, Brasil. Acta Veterinaria Brasilica, v. 9, n.1, p. 34-42, 2015.

TEIXEIRA, W.C.; SANTOS, H.P.; VESCHI, J.L.A.; NASCIMENTO, S.A.; SILVA, J.C.R.; MARVULO, M.F.V.; RIZZO, H.; CASTRO, R.S. Prevalência da infecção pelo Vírus da Artrite Encefalite Caprina em rebanhos caprinos do estado do Maranhão, Brasil. Revista Brasileira de Medicina Veterinária, v. 38, n.1, 2016. 